\title{
La retórica en internet: análisis de la persuación en los entornos virtuales
}

Rhetoric in the internet: Analysis of persuasion in virtual environments

\author{
Mónica Ilanda BriJaldo Rodríguez ${ }^{1}$ \\ Jorge EnriQue Rojas Otálora ${ }^{2}$
}

Resumen: El interés por los aspectos retóricos de internet es aún poco significativo en los encuentros adacémicos. El presente estudio quiere mostrar como la internet es, de hecho, un artefacto cultural y un medio en el cual se puede elaborar un discurso retórico pertinente. Por eso, se busca analizar y presentar cuáles serían los elementos o aspectos que todo espacio web debe desarollar y la manera como el discurso (multimedia) consigue persuadir a sua visitantes de la importancia de su contenido y logra mantenerlos como usuarios permanentes de su información.

Palabras-clave: Artefacto cultural; comunicación; discurso virtual; persuasión; retórica.

\begin{abstract}
Interest in the rhetorical aspects of the Internet is still not significant in academia. The present study intends to show how the Internet is, in fact, a cultural artefact and a medium in which a pertinent rhetorical discourse can be elaborated. Therefore, we seek to analyse and present what would be the elements or aspects that every web space should implement and how the (multimedia) discourse manages to persuade visitors of the importance of their content and manages to maintain them as permanent users.
\end{abstract}

Keywords: Cultural artefact; communication; virtual speech; persuasion; rhetoric.

1 Pontificia Universidad Javeriana. brijaldom@javeriana.edu.co.

2 Universidad Nacional de Colombia. jerojaso@unal.edu.co. 
Retórica en la comunicación web-Albaladejo (2004)

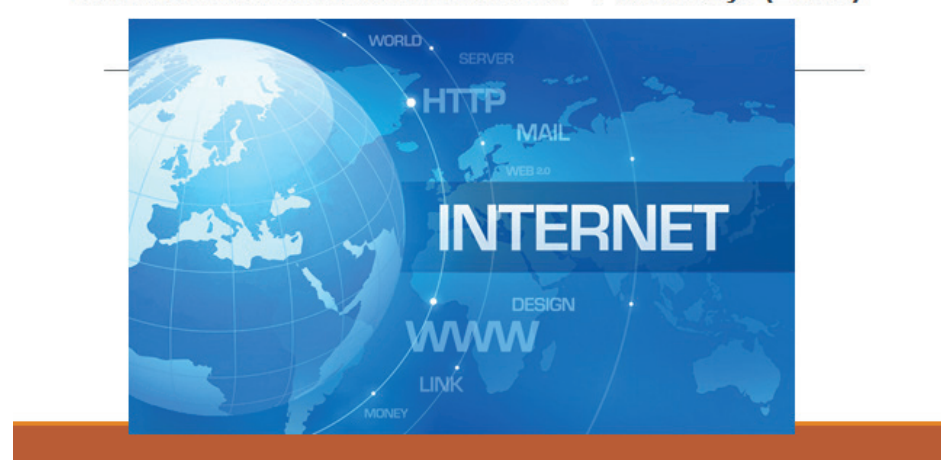

Aunque el interés por los aspectos retóricos de la internet ya tiene algunas décadas, el espacio que ocupa en estos encuentros académicos es aún poco significativo. Uno de los precursores de este tipo de estudios es el profesor Tomás Albaladejo de la Universidad Autónoma de Madrid, con un número considerable de trabajos al respecto. Es importante subrayar algunos elementos que este investigador destaca cuando estudia el carácter retórico de la comunicación que se produce en los sitios web.

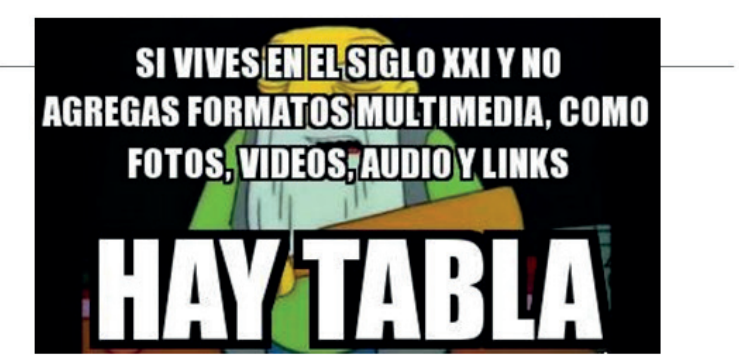

Una característica a tener en cuenta, en primer lugar, es la multimedialidad que, en el caso de la internet, responde a cambios sociales y tecnológicos en los cuales la retórica ocupa un lugar esencial como mecanismo de comuni- cación centrado en la persuasión. Aparte de la presencia real de discursos en la red, con una excelente efectividad comunicativa por su recurrencia, se debe destacar el papel de la retórica en la configuración de la web, pues como señala Albaladejo (2004):

\begin{abstract}
Quien elabora un sitio web, una página web, está llevando a cabo un proceso productivo retórico en cuanto a la organización semiótica del objeto significativo que construye: con la inventio obtiene y prepara los contenidos, con la dispositio los estructura, con la elocutio los expresa con todos los medios con los que cuenta y con la actio o pronuntiatio los comunica (p. 2).
\end{abstract}

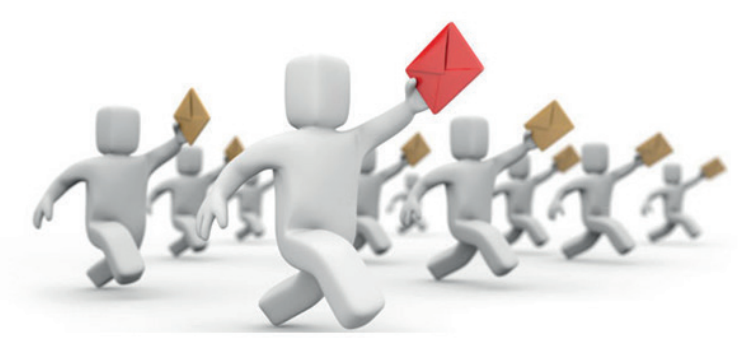

Del mismo modo, este autor enfatiza la finalidad persuasiva que rige la organización retórica del sitio web, de modo que a ella se orientan y dirigen tanto sus contenidos como la manera de estructurarlos, presentarlos y comunicarlos. Es fundamental comprender «a qué destinatarios quiere persuadir o convencer, en definitiva, en qué destinatarios quiere influir quien produce el sitio web» (p. 4). Por esta razón, insiste en que «el constructor del sitio web lleva a cabo, como en la 
producción de todo discurso retórico, la operación de intellectio, que le permite, entre otras cosas, conocer quiénes son sus receptores y cuáles son sus intereses, especialmente los que pueden incidir en la comunicación» (p. 4).

\section{Procesos metodológicos}

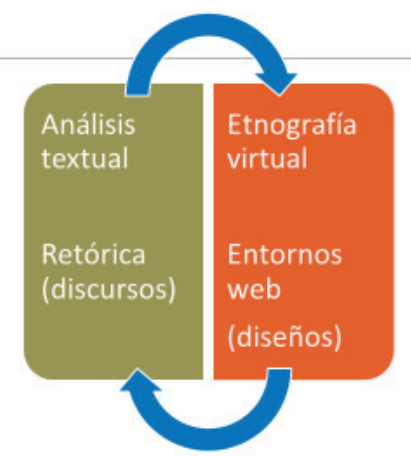

Para la propuesta metodológica que aquí se presenta conviene recordar que, según Albaladejo,

las modificaciones y transformaciones de la retórica no son sustitutivas sino coherentemente aditivas, de tal modo que hacen de la retórica un sistema en el que distintos componentes pueden estar inactivos mientras que otros están activos, pero existiendo siempre la posibilidad de que los inactivos sean activados si las necesidades y circunstancias de la comunicación y del análisis así lo exigen.

Para desarrollar el análisis retórico de la web se pretende indagar acerca de los discursos persuasivos en internet, por ello se trabajará desde procesos metodológicos complementarios: desde la etnografía virtual y desde el análisis textual. La etnografía virtual se define como metodología para investigar la cibercultura en la medida que se puedan explorar las interrelaciones existentes en los espacios virtuales. Christine Hine (2004) considera que la etnografía virtual problematiza el uso de Internet, puesto que el universo de la web adquiere sentido y sensibilidad con el uso. Desde este planteamiento define Internet como un artefacto cultural partiendo de la idea de que la tecnología, como los medios, posee flexibilidad interpretativa, en la medida en que su uso práctico se desarrolla en un contexto determinado.

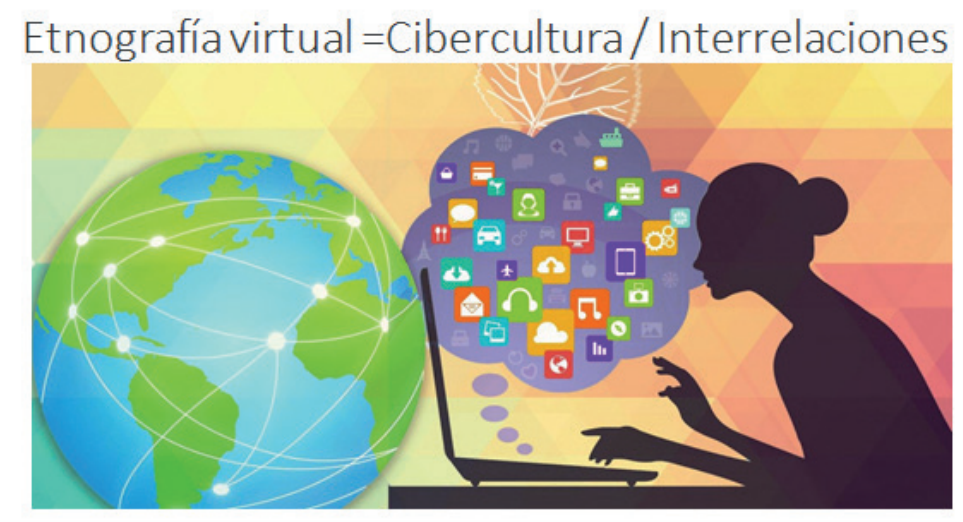

Cuando se habla de analizar Internet como un artefacto cultural se está haciendo referencia a todas las transformaciones, cambios y adaptaciones que sufren sus servicios a lo largo del tiempo y que ayudan a entender los rasgos propios y las condiciones de uso. Esto es lo que se llama «la metáfora de la tecnología como texto», cuando un diseñador lanza una nueva herramienta pensada para desarrollar ciertas actividades o tareas, no sabe a ciencia cierta cuál será su destino final. Esto ha pa- 
A continuación, se presentan los elementos constitutivos del discurso que se tendrán en cuenta en el análisis retórico de los sitios o espacios web a revisar.

\section{Elementos de análisis para los entornos virtuales}

Los entornos web poseen características muy diversas en su diseño, tanto por las temáticas que abordan, como por los objetivos que cada una de ellas persigue. El tema de cómo la retórica de los espacios web puede ayudar a identificar los elementos propios y necesarios de un entorno virtual, dependiendo de los intereses de sus diseñadores, es el propósito de este concepto novedoso. La retórica de la internet o ciberretórica se define como la forma de persuasión de los espacios en internet, «por el componente metafórico de su diseño y de los vocablos que definen su práctica contemporánea» (Berlanga e García, 2014, 145).

Desde esta perspectiva de observar los entornos virtuales como sistemas retóricos, se busca analizar y presentar cuáles serían los elementos o aspectos que todo espacio web debe desarrollar y la manera como el discurso - entendido este, no solo como texto, sino todos los formatos que permite internet, audio, video, imágenes, interacción, entre otras- consigue persuadir a sus visitantes de la importancia de su contenido y logra mantenerlos como usuarios permanentes de su información.
En los contextos educativos, es usual que los entornos web que se diseñan no tengan una aceptación constante de los usuarios, ya sea porque sus discursos suelen ser poco atractivos o porque solo interesan a unos pocos visitantes de la internet. De ahí la importancia de establecer cómo y de qué manera realizar un diseño de entorno digital favorable para la visibilidad, permanencia y calidad de los espacios de internet, como una forma de asegurar su efectividad en términos de persuasión y de convicción.

Partiendo de los dos ejes de sistematización retórica (texto retórico y hecho retórico), esquematizados en la Figura 1 (Albaladejo, $1991,44)$ - en los cuales el eje vertical corresponde a las operaciones de producción retórica (actividad del orador) y el eje horizontal a la estructuración del texto en distintas partes, orientada por lo tanto al proceso de recepción que realiza el destinatario del discurso (característica del receptor) - , se proponen los elementos que desde el análisis retórico se podrían hallar en los diferentes espacios web. En la medida en que estos ejes se interrelacionan en su funcionamiento, la presentación partirá de la intellectio y seguirá por el eje vertical con la inventio, pero en este momento se orientará hacia el eje horizontal con el exordium y se seguirá moviendo alternativamente para mostrar precisamente esa interrelación. 


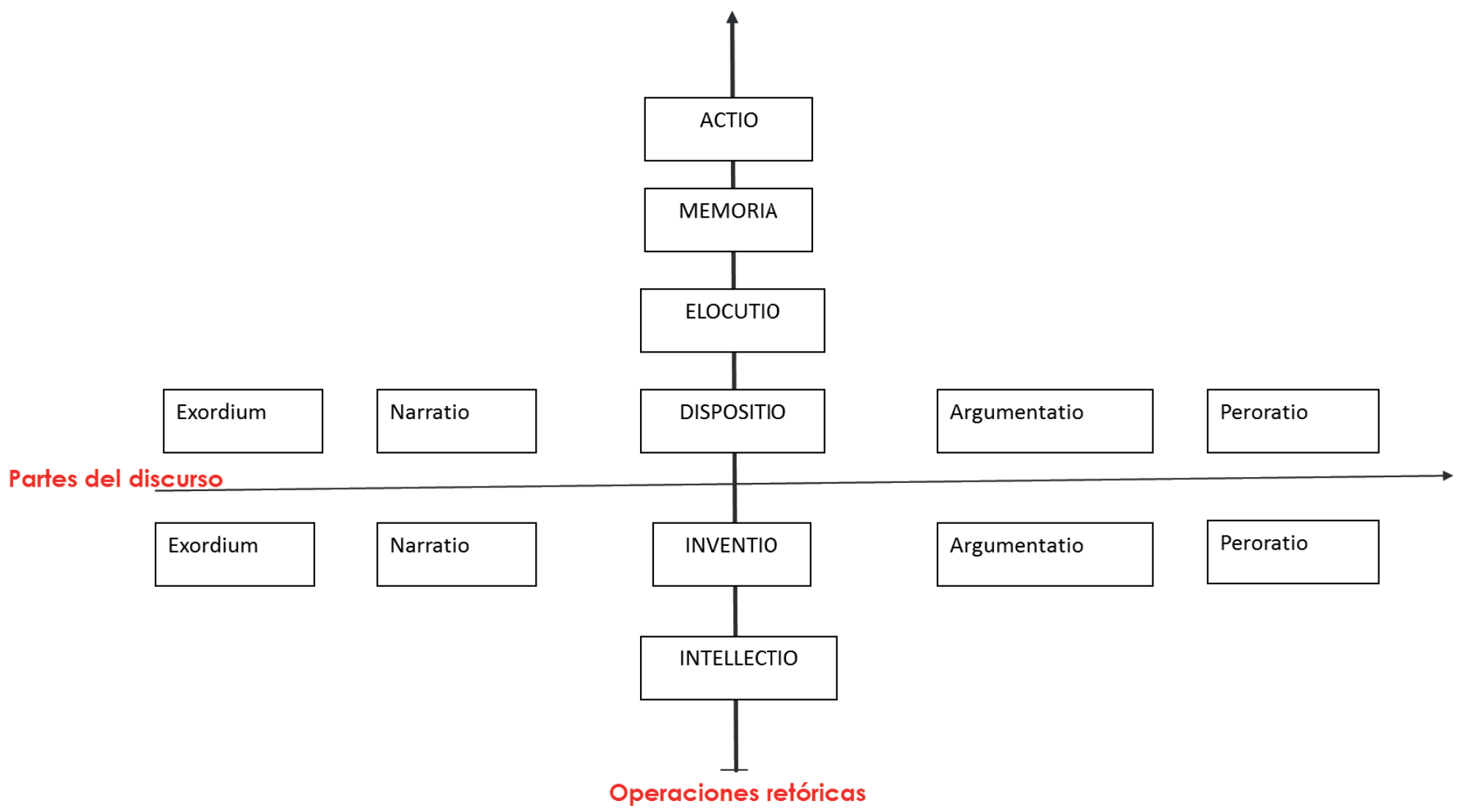

Figura 1 - Ejes de sistematización retórica (Albaladejo,

1991)

\section{Análisis retórico de la web}

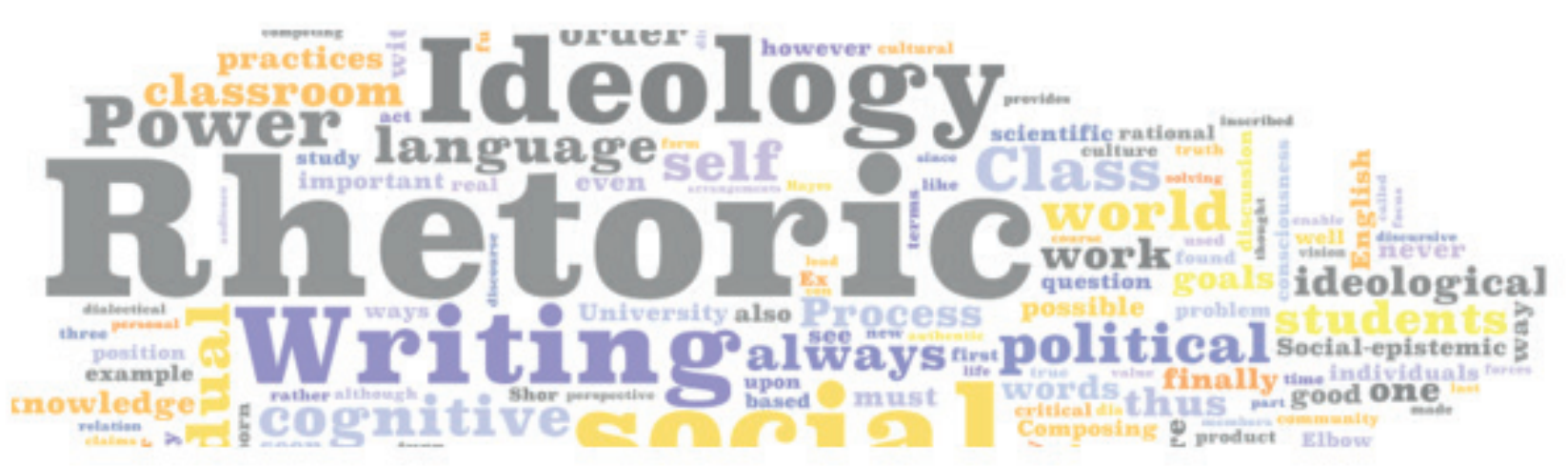




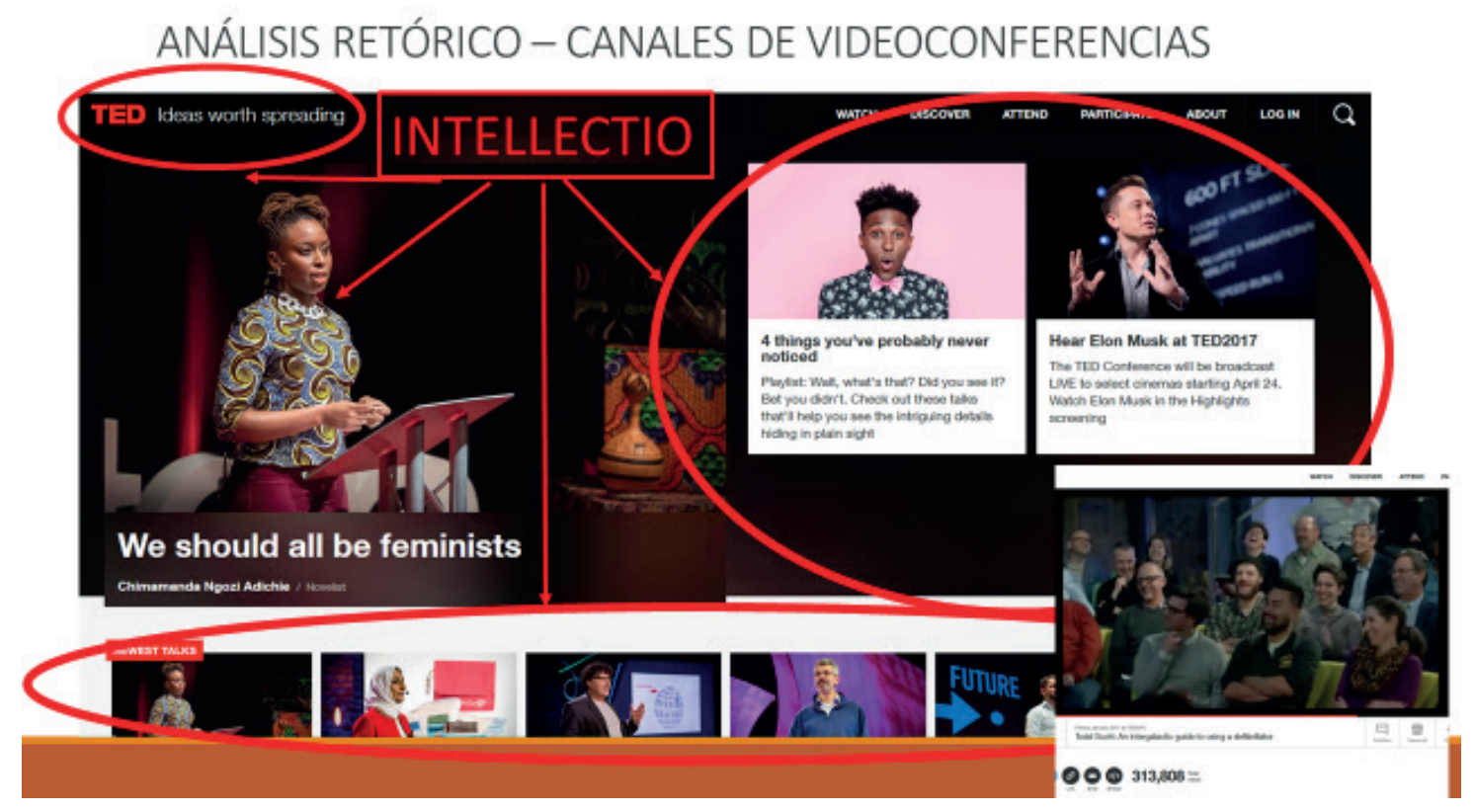

\section{Operaciones retóricas/partes del discurso}

Son las operaciones que tienen lugar en la producción del discurso retórico.

\section{Intellectio}

Es la operación retórica de análisis antes de comenzar la producción del texto retórico, por lo cual se define como el espacio de creatividad e ingenio del diseñador. Este aspecto es muy importante, pues es el momento en el cual el creador define el diseño, los contenidos y los usuarios a los cuales va dirigido su entorno. También es el espacio en el que se configura el discurso para la inventio y la dispositio y en dónde se define la finalidad del entorno virtual; en otras palabras, donde se perfila a los usuarios y la manera como se van a persuadir o a convencer de permanecer en este entorno virtual. Aquí interviene la poliacroasis, que se define como un elemento fundamental para establecer los tipos de oyentes y el tipo de discurso a desarrollar.

Para ejemplificar este funcionamiento se ha escogido la página de TED ${ }^{3}$. Se observa que el diseño de esta página expresa muy bien las ideas y los contenidos del sitio. Antes más, la frase que distingue a TED — «ldeas dignas de difundir» - inicia el proceso de persuasión, que se complementa cuando aparece información sobre charlas futuras o información de interés para los usuarios, bien como la variedad de temas sobre los cuales existen charlas y el esquema de conferencia con público presencial y la figura del experto. En cuanto a la distribución de los elementos de la pantalla, el diseñador ha tenido en cuenta el efecto que debe causar en el usuario, por lo cual el diseño es limpio, agradable, sin recargas de información, así

\footnotetext{
${ }^{3}$ https://www.ted.com/
} 
como el manejo oscuro del fondo que favo-

rece al consumo de energía.

\section{ANÁLISIS RETÓRICO - OPERACIONES RETORICAS}

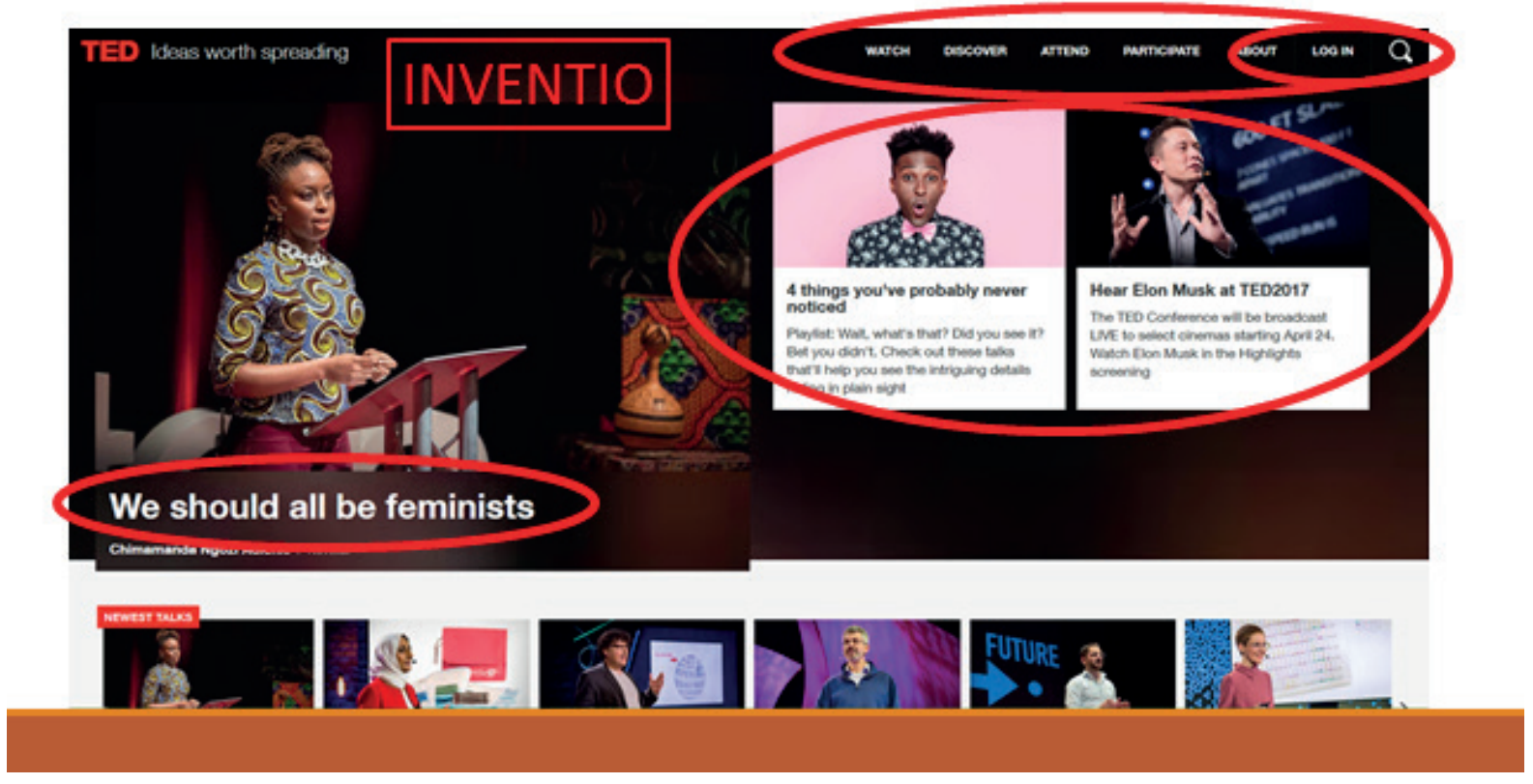

Inventio

Berlanga \& García (2014), al definir el discurso retórico desde el concepto de hipertexto, anotan que el primer procedimiento que desarrolla un diseñador web es la búsqueda de temas y argumentos para su discurso hipermedial, de la misma manera que el orador retórico busca las palabras para fundamentar su persuasión. Alayón (2009) habla de «repertorios hiperclasificados en la web donde puede obtenerse signos lingüís- ticos, visuales y auditivos que van a ser reconocidos inmediatamente por los receptores de su discurso hipertextual, como signos persuasivos válidos». Por ello, la estructura del contenido del entorno (menús, partes del sitio, la inscripción de los usuarios, entre otros) permite identificar a los visitantes-lectores permanentes y a los enlaces de interés. Este mecanismo constituye la caracterización de la inventio. 


\section{ANÁLISIS RETÓRICO - OPERACIONES RETORICAS}
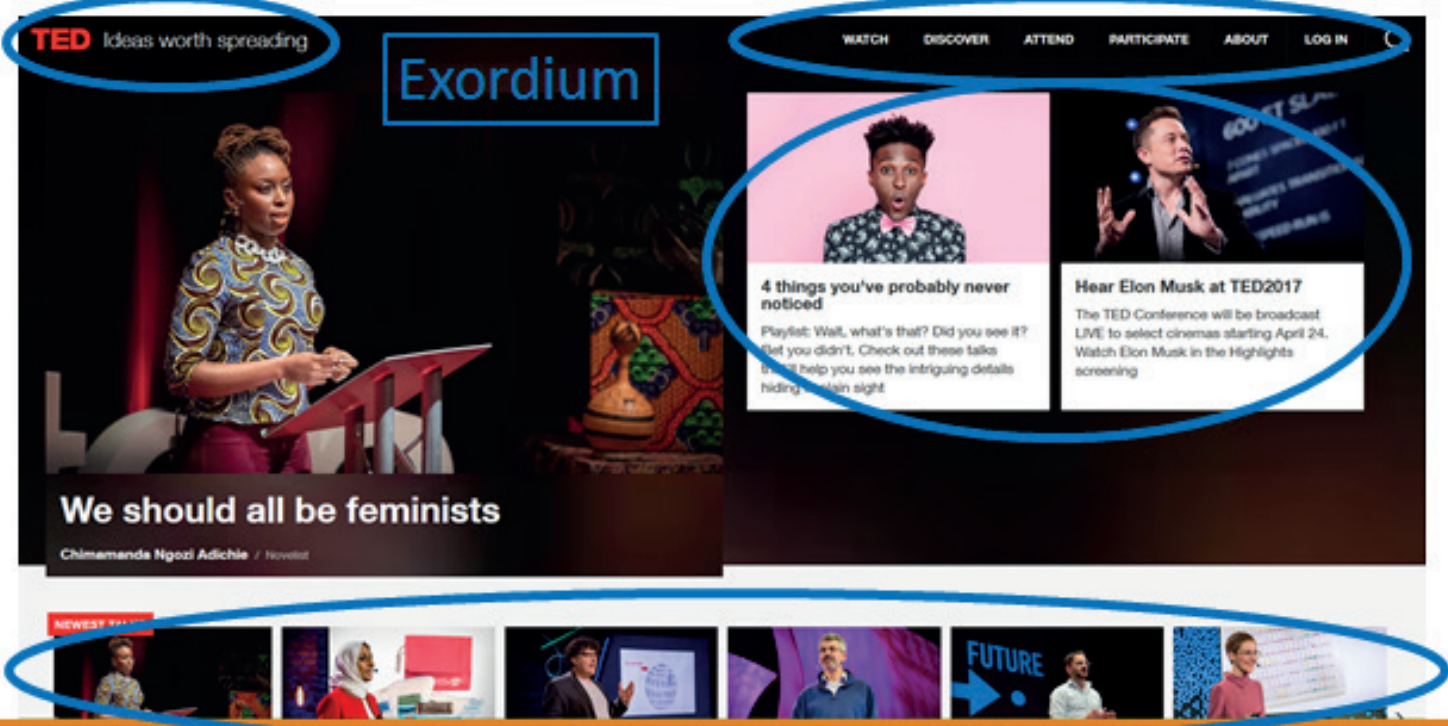

\section{Exordium}

Siendo la parte inicial del discurso retórico, que presenta la causa ante el receptor, se entiende el exordium como el ingreso a la página o entorno web. Esta página de inicio contiene los primeros elementos visuales y/o auditivos que captan la atención del visitante y le llevan a seguir navegando por el sitio. Por ello, el análisis retórico contempla elementos del diseño de la interfaz, los atributos del entorno web, las rutas de navegación, el mapa del sitio y los servicios asociados; pero también el tipo de información que se maneja y la pertinencia de los contenidos. Con esta primera parte del discurso se logra captar la atención del usuario al entorno virtual.

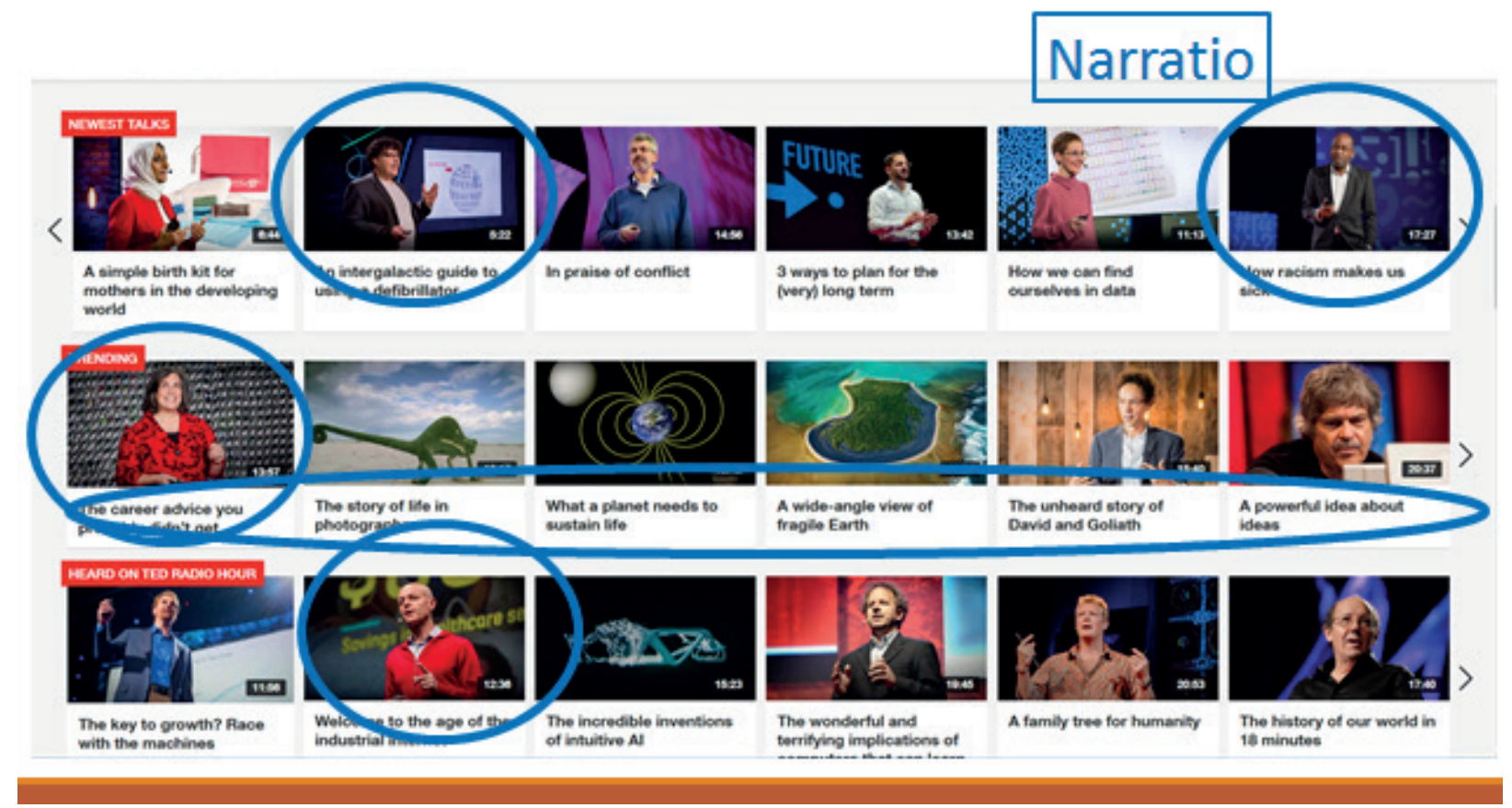




\section{Narratio}

Al ser la parte de exposición de los hechos, se busca que el usuario tenga un conocimiento más claro de los contenidos. Es el tránsito entre lo emocional y lo intelectual, cuyo objeto es exponer el relato de los acontecimientos, desde la mirada del orador. Se ubican en este aspecto la presentación de una amplia oferta temática y, en el caso del discurso digital, la confiabilidad de los contenidos y el uso de los diferentes formatos de información, como en esta charla - Guía intergaláctica de cómo utilizar un desfibrilador - que cumple el objetivo primordial de lograr la adhesión de los visitantes-lectores al sitio.

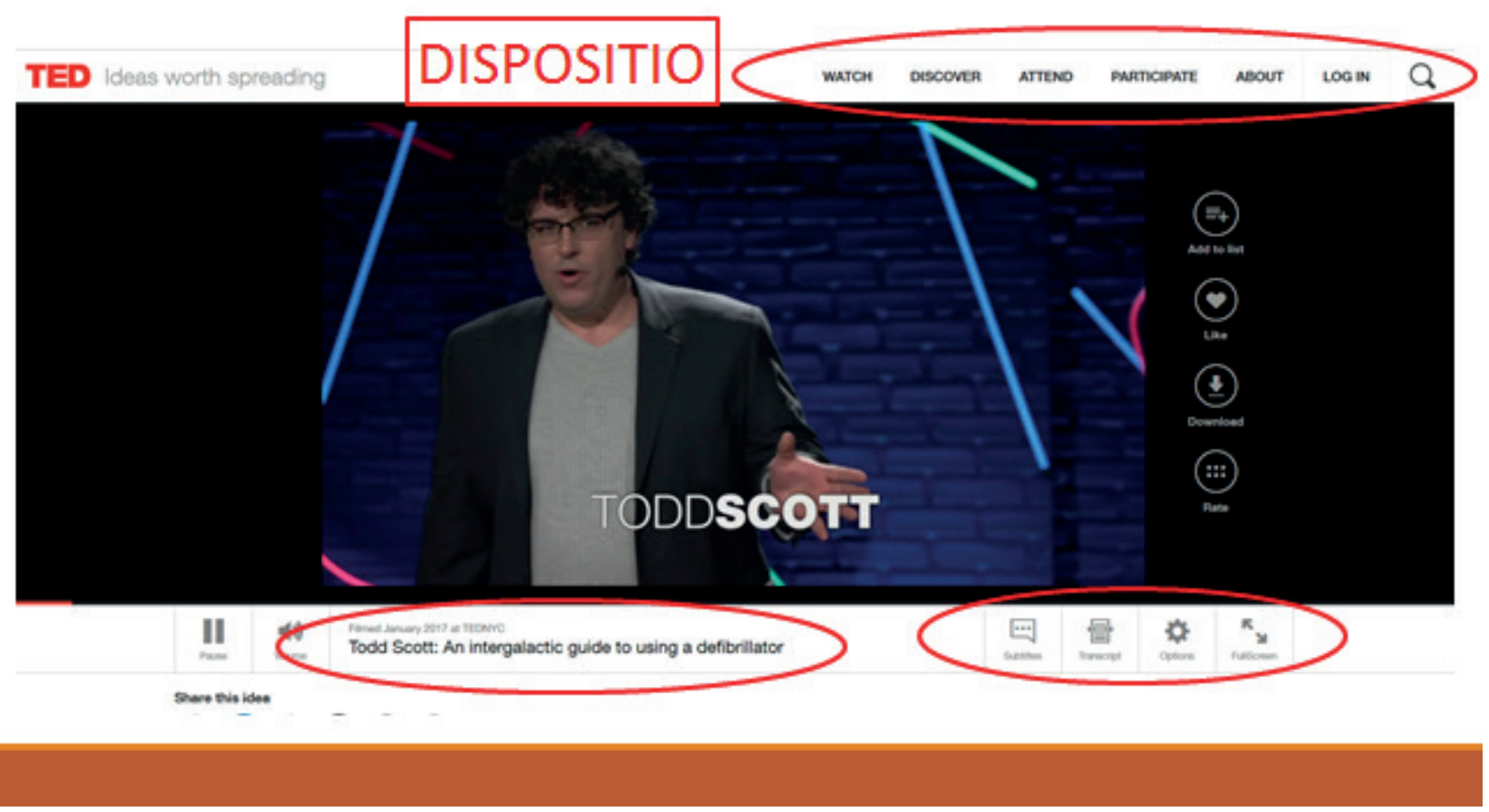

\section{Dispositio}

Al representar la ordenación y distribución de las cosas, se debe mencionar la libertad que tiene el usuario del espacio web para elegir sus propios itinerarios de lectura. Como en el caso al seleccionar la charla referida arriba. Los menús diseñados y el orden en el que aparecen en la web pueden determinar la manera en que se ingresa a cada espacio, o inclusive la facilidad de encontrar el lugar exacto al que se quiere ingresar. Buena parte de este orden de lectura estará determinado por la distribución del contenido, los servicios informativos que proporcionen los botones, enlaces y vínculos a redes sociales, pero sobre todo por los intereses particulares de los usuarios y sus múltiples posibilidades de navegación. 


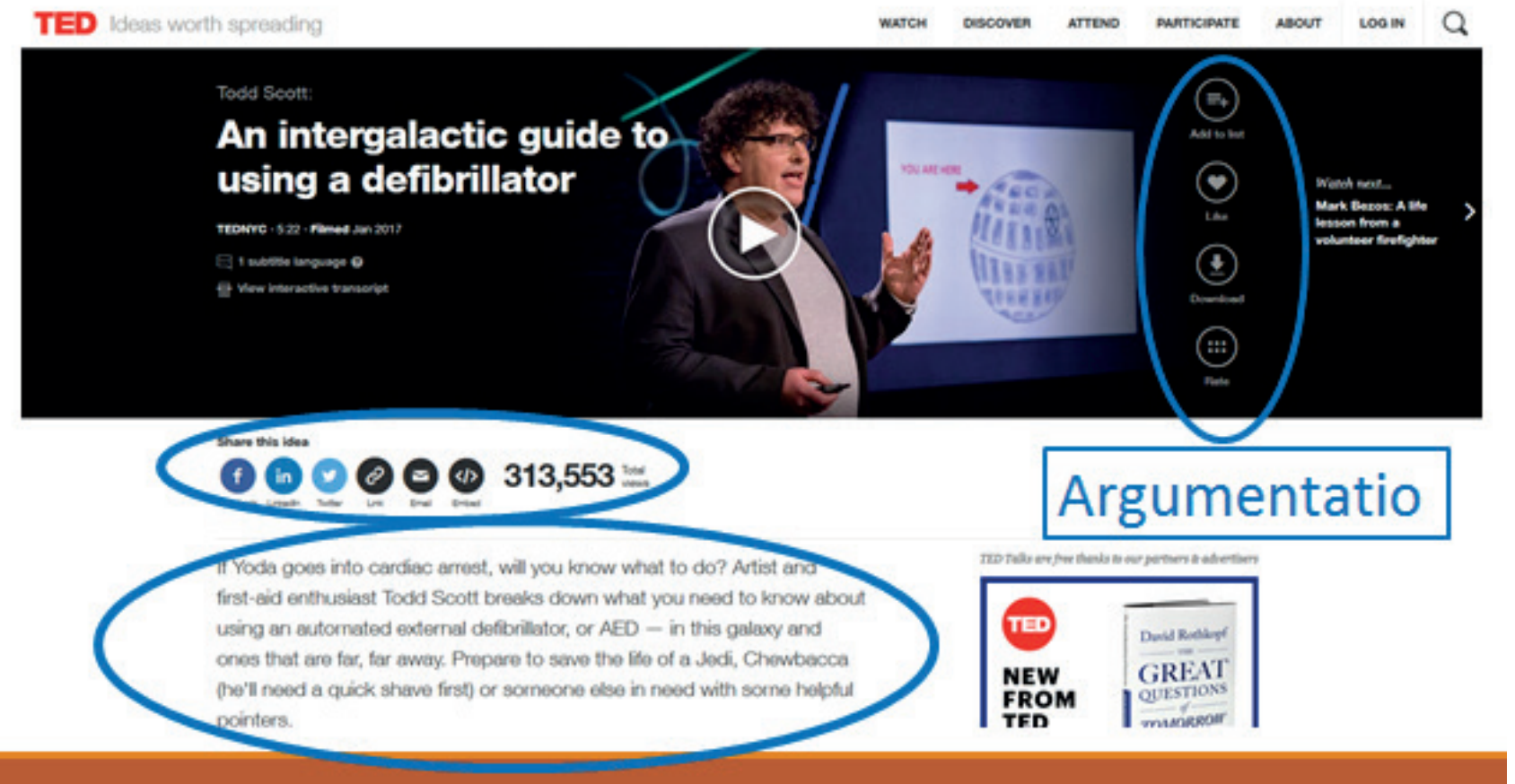

\section{Argumentatio}

Este elemento organiza la estructura del discurso digital a partir de la exposición de ideas, conceptos y argumentos que consolidan los contenidos presentados; lo constituye el desarrollo intelectual de los argumentos y pruebas. En este aspecto es importante lograr la participación de los oyentes-usuarios; lograr la interacción con los usuarios del entorno web es fundamental. En los espacios virtuales, los esquemas de redes sociales o de sitios de discusión permiten que los usuarios puedan comentar, argumentar o contra-argumentar frente a la información que el sitio web dispone y se valora la capacidad de los usuarios de modificar o actualizar los contenidos y darle confiabilidad a la información mediante la discusión y la participación.

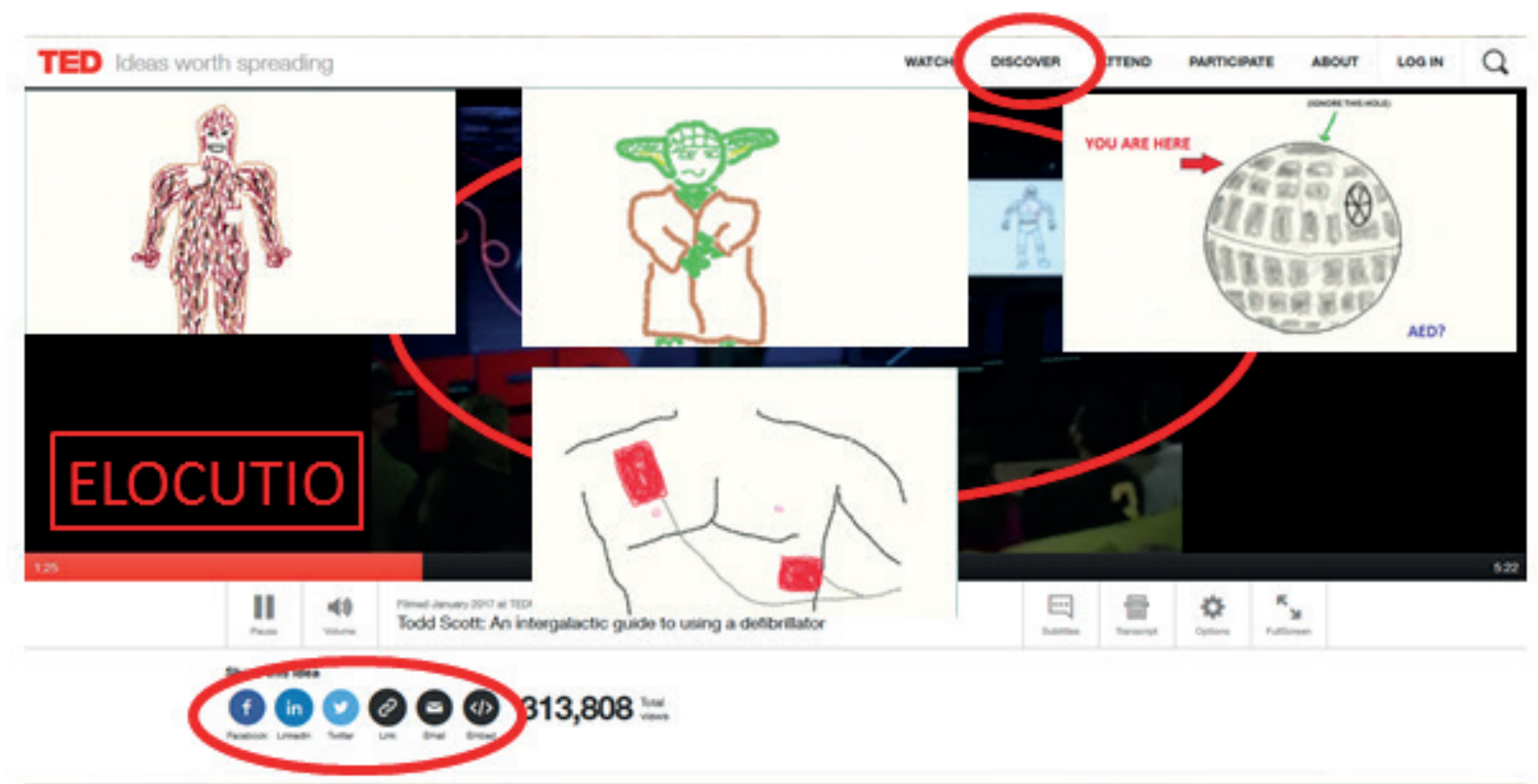




\section{Elocutio}

Si se acepta, como propone Albaladejo (1991, 117), que la elocutio debe manifestar la construcción macroestructural correspondiente al nivel de la dispositio, se puede observar esta misma estructuración en los servicios que presta el espacio web, tales como: sistemas de búsqueda, conexión con expertos, contacto con otros usuarios y páginas relacionadas. La elocutio debe manifestar adecuadamente los contenidos del discurso con el fin de que el orador alcance la finalidad que pretende con relación al destinatario (Albaladejo, 1991). Como es el caso de esta conferencia que desarrolla una puesta en escena a partir de los personajes de La Guerra de las galaxias. Funcionan en este mismo sentido los elementos de participación y de calificación que establecen los usuarios a los sitios y su percepción sobre ellos, la denominada folksonomía, y todos los llamados procesos de fidelización.

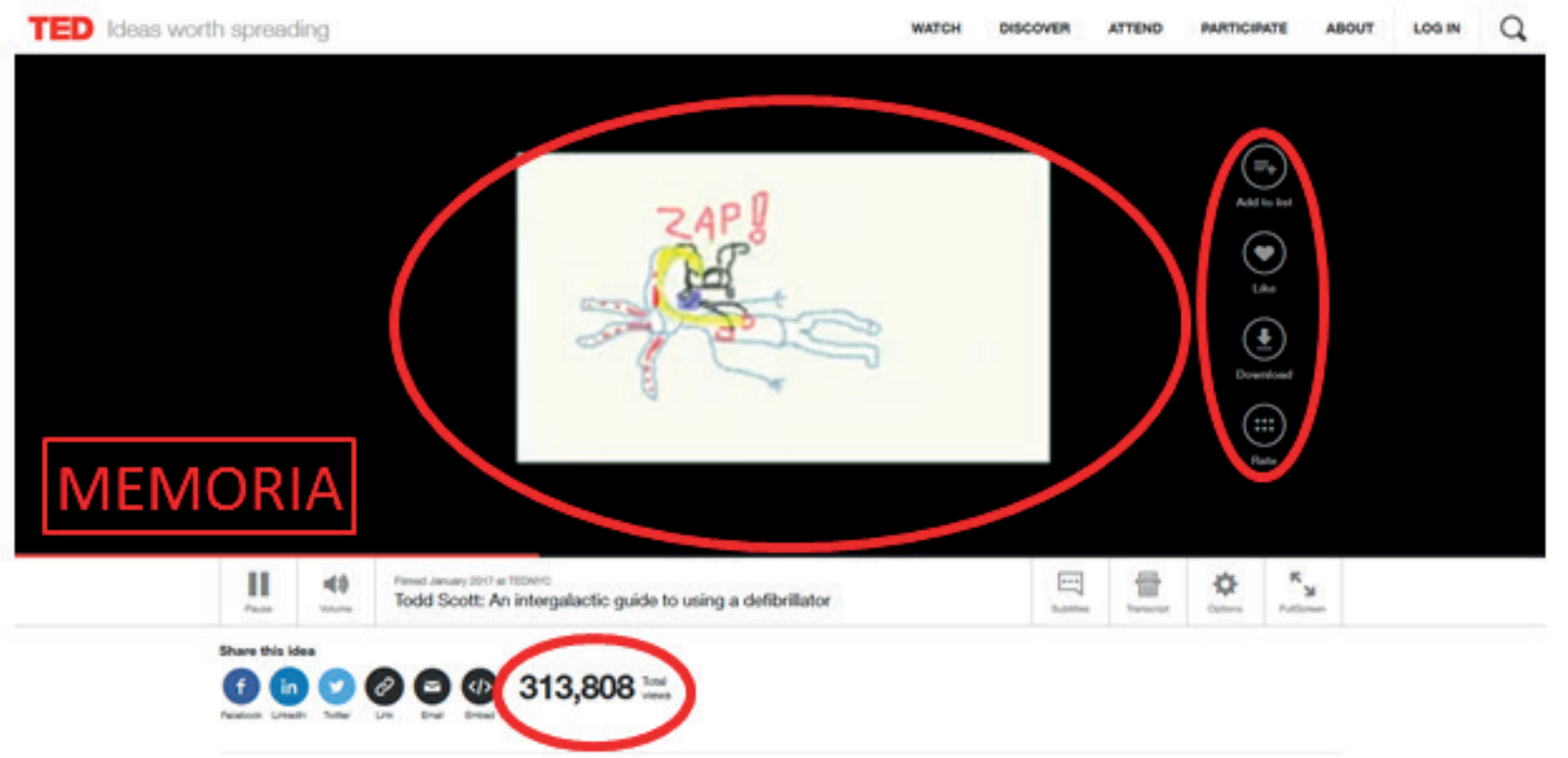

\section{Memoria}

En este caso, se define como el ingenio del diseñador del entorno virtual y su capacidad para elaborar un sistema de recuperación de información, así como de establecer el perfil de los usuarios que visitan el sitio. En este elemento se examina la capacidad de recuperar y mantener información de tiempo atrás, el análisis de los usuarios mediante las estadísticas y las aplicaciones empleadas y la posibilidad de revisar los múltiples discursos digitales y los oyentes de estos discursos en el tiempo. 


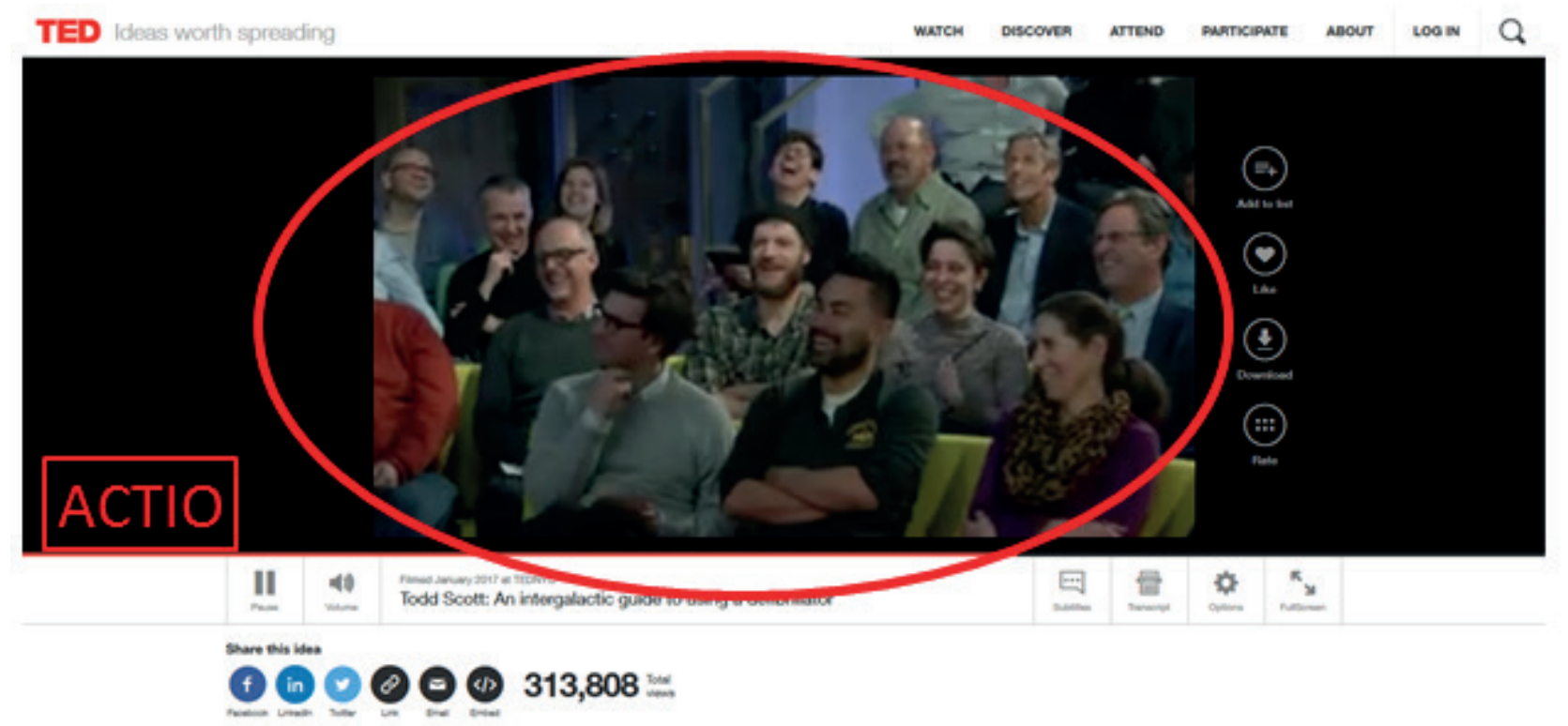

\section{Actio}

Siendo la actio la emisión del discurso retórico, se entiende como la interactividad y actualización del entorno de acuerdo con el pú- blico al cual es dirigido. Por esto, la atención al usuario, la participación y la actualización del entorno constituyen esa puesta en escena del sitio, que lo mantiene activo y funcionando.

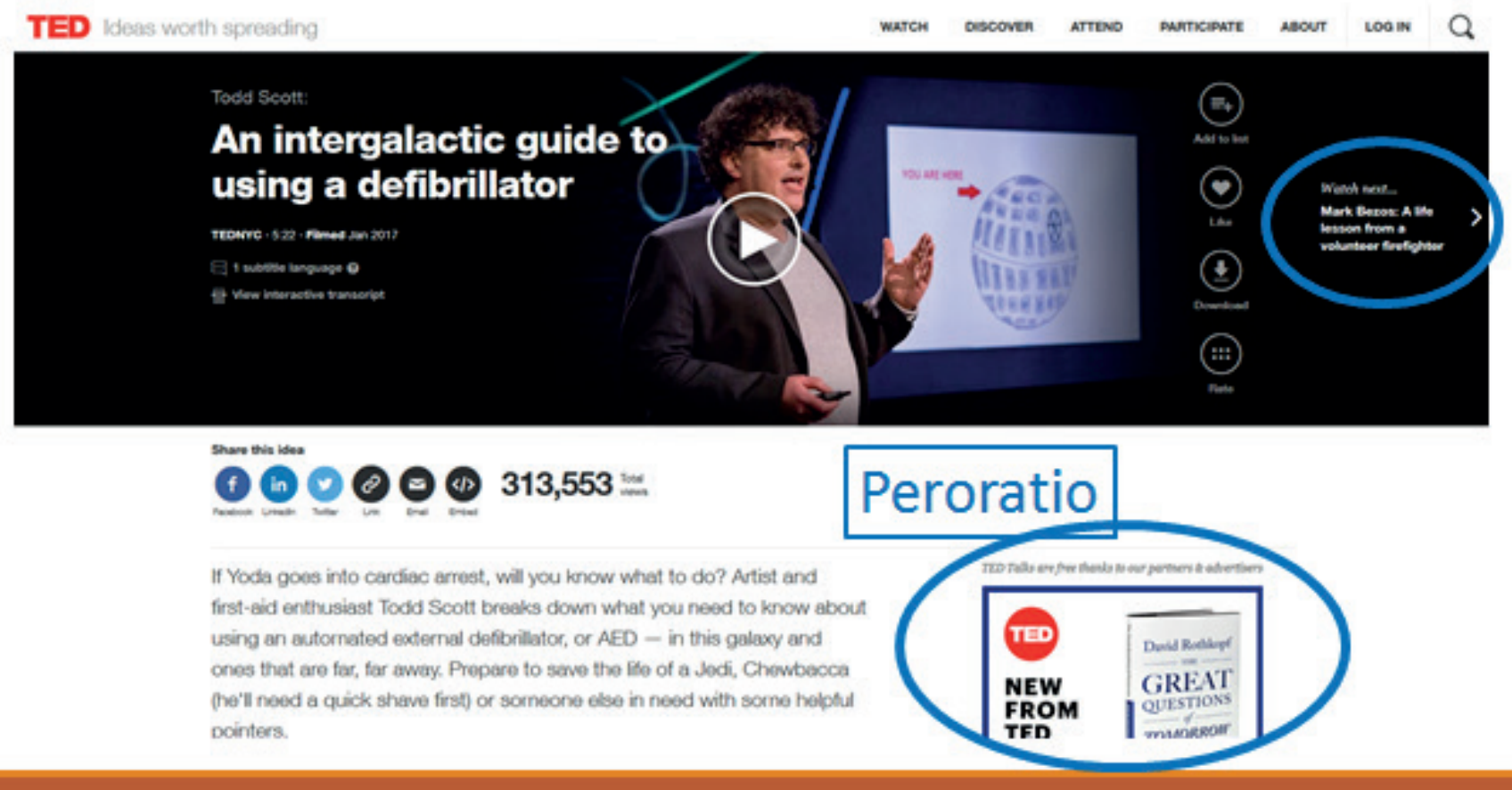




\section{Peroratio}

Es el último intento persuasivo, pues apela a las emociones del usuario haciendo un recuento de lo tratado. En los entornos web se utilizan los Pop up, que son ventanas que se despliegan cuando el usuario quiere abandonar el sitio y le ofrecen nuevas posibilidades de información, o le invitan a visitar otros sitios relacionados, o a mantenerse en la página actual con la entrega de ofertas, regalos o acceso a información que hasta ese momento no se ha visitado. En otros casos, se persuade del abandono con imágenes que golpean la emoción del usuario (por ejemplo: niños o muñecos llorando y pidiendo que no abandones la página).

En cuanto a los contenidos, se busca que la participación de los usuarios enfoque los temas de interés o se establezcan los medios y objetos de análisis de contenidos asociados a la información cotidiana del sitio web.

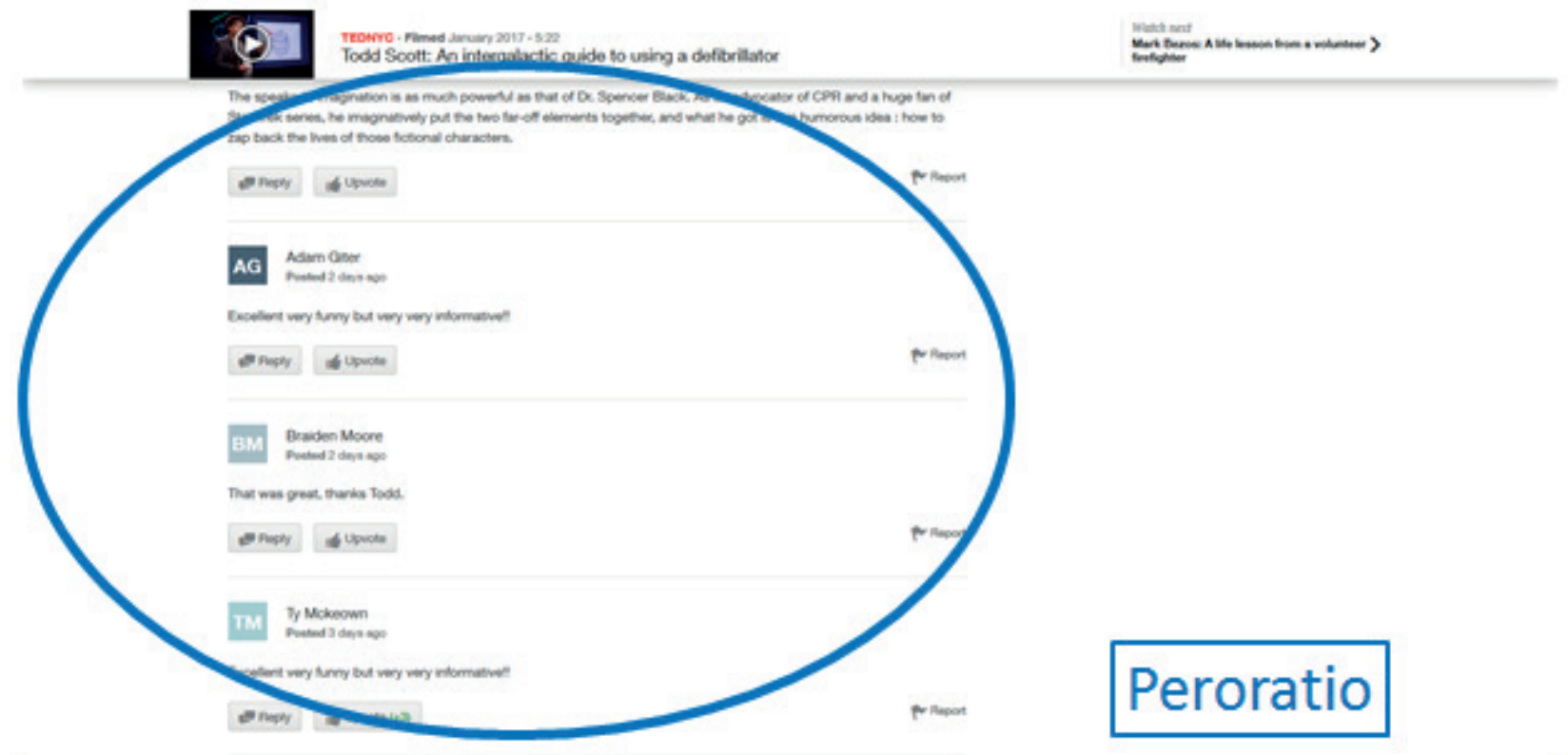


Es importante resaltar que los entornos educativos en la red son poco atractivos porque se enfocan en el manejo del texto, casi de manera exclusiva, y con frecuencia se elaboran sin una intellectio definida, aunque su contenido en sí mismo pueda ser particularmente valioso. El desarrollo de cursos de acceso libre como los MOOC, aunque empiezan a cambiar esta dinámica de amplios contenidos y poca interactividad, aún se concentran en la distribución de información, más que en el diseño de un entorno persuasivo que logre adherir más usuarios.

Para finalizar, se debe reconocer que, en los contextos educativos, el tema de la persuasión suele tener una connotación negativa, en la medida en que se le relaciona con el convencimiento sin análisis o reflexión previa, incluso como una manipulación consciente de quién quiere persuadir, y de una aceptación pasiva por parte de quién escucha el discurso persuasivo. Por esto, con el análisis retórico, se espera lograr que quién diseña un entorno web, considere las intencionalidades, expresas o no, que orientan su sitio y planee un espacio en internet que tenga en cuenta a la colectividad dentro de un manejo responsable de los contenidos y de las interacciones de sus usuarios, tanto en el contexto educativo, cómo en otros sitios desarrollados con intencionalidad formativa.

\section{Bibliografía}

Alayón, J. (2004). Retórica y discurso hipertextual. Del trovador oral al trovador hipermedial: notas para un estudio. Ponencia presentada en el II Congreso de la Cibersociedad. Observatorio para la CiberSociedad. Biblioteca Virtual Miguel de Cervantes. Barcelona (España);

Albaladejo Mayordomo, T. (1991). Retórica. Editorial Síntesis. Madrid;

Albaladejo Mayordomo, T. (2004). La comunicación retórica en los sitios web. Ponencia presentada en el II Congreso de la Cibersociedad. Observatorio para la CiberSociedad. Barcelona (España);

Berlanga, I. y García, F. (2014). Ciberretórica: Aristóteles en las redes sociales. Manual de retórica en la comunicación digital. Editorial Fragua. Madrid;

Berlanga, I. y Martínez, E. (2010). Ciberlenguaje y principios de retórica clásica. Redes sociales: el caso Facebook. Enl@ce Revista Venezolana de Información, Tecnología y Conocimiento, 7 (2), 47-61;

Bernal Leongómez, J. (1986). Antología de lingüística textual. Instituto Caro y Cuervo. Bogotá;

Beristáin, H. (1992) Diccionario de retórica y poética. (3. ${ }^{a}$ ed). Porrúa. México;

Cabezuelo, F. y González, A. (2014). El twitter de Aristóteles. Una revisión de los conceptos clásicos de la retórica clásica en la actual sociedad digital. Revista de Comunicación Vivat Academia. DOI: http://dx.doi.org/10.15178/ va.2014.126.20-30;

Hine, C. (2004). Etnografía virtual. Editorial UOC. Barcelona;

Navarro, B. (2003). Aspectos retóricos-comunicativos del desarrollo de sitios web. En: In- 
ternational Society for the History of Rhetoric. XIV Biennal Conference. Madrid y Calahorra;

Pernot, L. (2013). La retórica en Grecia y Roma. UNAM. México;

Ramírez Vidal, G. (2005). La palabra y la flecha. Análisis retórico de textos de la Grecia antigua. UNAM. México;
Tapia, A. (2010). La persuasión por el orden. Una revitalización de la dispositio retórica. En: H. Beristáin y G.R. Vida (Comp.). Espacios de la retórica. Problemas filosóficos y literarios. UNAM. México. pp. 275-284. 